\title{
Erratum to: Hemoptysis, Endoscopic Management
}

\author{
Rosa Cordovilla, Elena Bollo de Miguel, \\ and Juan Alejandro Cascón Hernández
}

\section{Erratum to:}

Chapter 38 in: J.P. Díaz-Jimenez, A.N. Rodriguez (eds.), Interventions in Pulmonary Medicine, https://doi.org/10.1007/978-3-319-58036-4_38

Elena Bollo de Miguel and Juan Alejandro Cascón Hernández were not listed among the authors and now they are added to the chapter.

R. Cordovilla, MD

Pulmonary Department, University of Salamanca,

Salamanca University Hospital,

$\mathrm{P}^{\circ}$ San Vicente 58, 37007 Salamanca, Spain

e-mail: rcordovilla@usal.es;

rosacordovilla@gmail.com

E.B. de Miguel, MD

Pulmonary Department, University Hospital of León,

León, Spain

e-mail: ebollo@ono.com

J.A. Cascón Hernández, MD

Pulmonary Department, Salamanca University Hospital,

Salamanca, Spain

e-mail: jcasconh@gmail.com

The updated online version of this chapter can be found at https://doi.org/10.1007/978-3-319-58036-4_38 